\title{
Downregulation of Functional Reelin Receptors in Projection Neurons Implies That Primary Reelin Action Occurs at Early/Premigratory Stages
}

\author{
Takayuki Uchida, ${ }^{1}$ Atsushi Baba, ${ }^{1}$ F. Javier Pérez-Martínez, ${ }^{2}$ Terumasa Hibi, ${ }^{1}$ Takaki Miyata, ${ }^{3}$ Juan M. Luque, ${ }^{2}$ \\ Kazunori Nakajima, ${ }^{4}$ and Mitsuharu Hattori ${ }^{1}$ \\ ${ }^{1}$ Department of Biomedical Science, Graduate School of Pharmaceutical Sciences, Nagoya City University, Mizuho-ku, Nagoya, Aichi 467-8603, Japan, \\ ${ }^{2}$ Laboratory of Molecular Neuroanatomy, Instituto de Neurociencias, University Miguel Hernandez-Consejo Superior de Investigaciones Cientificas, \\ San Juan de Alicante, E-03550, Spain, ${ }^{3}$ Department of Anatomy and Cell Biology, Nagoya University School of Medicine, Showa-ku, Nagoya, Aichi \\ 466-8550, Japan, and ${ }^{4}$ Department of Anatomy, Keio University School of Medicine, Shinjuku-ku, Tokyo 160-8582, Japan
}

Reelin signaling is essential for correct development of the mammalian brain. Reelin binds to apolipoprotein E receptor 2 and very low-density lipoprotein receptor and induces phosphorylation of Dab1. However, when and where these reactions occur is essentially unknown, and the primary function(s) of Reelin remain unclear.

Here, we used alkaline phosphatase fusion of the receptor-binding region of Reelin to quantitatively investigate the localization of functional Reelin receptors (i.e., those on the plasma membrane as mature forms) in the developing brain. In the wild-type cerebral cortex, they are mainly present in the intermediate and subventricular zones, as well as in radial fibers, but much less in the cell bodies of the cortical plate. Functional Reelin receptors are much more abundant in the Reelin-deficient cortical plate, indicating that Reelin induces their downregulation and that it begins before the neurons migrate out of the intermediate zone. In the wild-type cerebellum, functional Reelin receptors are mainly present in the cerebellar ventricular zone but scarcely expressed by Purkinje cells that have migrated out of it. It is thus strongly suggested that Reelin exerts critical actions on migrating projection neurons at their early/premigratory stages en route to their final destinations, in the developing cerebral cortex and cerebellum.

\section{Introduction}

Reelin is a secreted glycoprotein essential for brain development (D’Arcangelo et al., 1995). When Reelin is deficient, migration of many projection neurons such as pyramidal neurons in cerebral cortex and Purkinje cells in cerebellum become aberrant, and they eventually reside in abnormal positions (for review, see Tissir and Goffinet, 2003). Reelin is highly expressed near where those neurons target and/or stop: the marginal zone (MZ) in the developing cerebral cortex (D'Arcangelo et al., 1995; Ogawa et al., 1995), and the nuclear transitory zone (NTZ) and the external granular layer (EGL) in the developing cerebellum (Miyata et al., 1996). Proposed functions of Reelin include stop, detach, permissive, attractive, and branch-inducing signals, but none of these alone can explain all the phenotypes observed in the Reelindeficient mouse, reeler (Tissir and Goffinet, 2003; Soriano and

Received Jan. 22, 2009; revised July 1, 2009; accepted July 21, 2009.

This work was supported by Grants-in-Aid for Scientific Research from the Ministry of Education, Science, Sports, and Culture (M.H., A.B.), Ono Medical Research Foundation, and Kanae Foundation for the Promotion of Medical Science (M.H.). T.H. is a Research Fellow of Japan Society for the Promotion of Science. J.M.L. is a Ramón y Cajal Research Fellow funded by Grant SAF2004-07685 and Fundación Mutua Madrileña. We thank the members of our laboratories for helpful comments and discussions.

Correspondence should be addressed to Mitsuharu Hattori, Department of Biomedical Science, Graduate Schoo of Pharmaceutical Sciences, Nagoya City University, 3-1 Tanabe-dori, Mizuho-ku, Nagoya, Aichi 467-8603, Japan. E-mail:mhattori@phar.nagoya-cu.ac.jp.

DOI:10.1523/JNEUROSCI.0345-09.2009

Copyright $\odot 2009$ Society for Neuroscience $\quad$ 0270-6474/09/2910653-10\$15.00/0
Del Río, 2005; Luque, 2007; Cooper, 2008). Reelin binds to apolipoprotein E receptor 2 (ApoER2) and very-low-density lipoprotein receptor (VLDLR) (D'Arcangelo et al., 1999; Hiesberger et al., 1999) and then induces tyrosil phosphorylation of an intracellular protein, Dab1 (Howell et al., 1999). Dab1 is then ubiquitinated and degraded, which is necessary for correct layer formation in the forebrain (Feng et al., 2007). Importantly, when and where these reactions occur has not been fully elucidated because the precise localization of "functional Reelin receptors" (FRRs) (the receptors on the plasma membrane as fully mature form) is not known, because ApoER2 and VLDLR undergo regulated and complicated intracellular trafficking (D'Arcangelo et al., 1999; Morimura et al., 2005; Hoe et al., 2008) (for review, see Stolt and Bock, 2006).

Generally, it is not easy to ascertain the localization and total amount of functional receptors to a certain ligand. RNA in situ hybridization can be highly specific and sensitive, but it provides no information on the subcellular localization of the protein and may not even reflect the amount of mature protein. Immunohistochemical analysis is often complicated by the cross-reactivity of the antibody with other proteins and degraded products. Most importantly, when there is more than one receptor molecule performing similar functions, these techniques do not allow ascertainment of their "total" amounts because the intensity of the signals derived from different probes or antibodies cannot be quantitatively compared or accumulated. In the case of Reelin 
receptors, the genetic evidence suggests that ApoER2 and VLDLR function mostly in a redundant manner (Trommsdorff et al., 1999), although each of them may have its own specific roles (Benhayon et al., 2003; Hack et al., 2007). Furthermore, ApoER2 binds to Reelin more strongly than VLDLR (Andersen et al., 2003), further complicating the interpretation.

Utilization of the alkaline phosphatase (AP)-fusion probe is a sensitive and easy method for quantifying protein-protein interactions in the extracellular milieu (Flanagan et al., 2000). Here we used AP fusion of the receptor-binding unit of Reelin to quantitatively localize the total amount of FRRs in the developing brains of wild-type and mutant mice, showing that regulated expression and downregulation of FRRs underlie migration of both cortical and cerebellar projection neurons, particularly at their early/ premigratory stages.

\section{Materials and Methods}

Animal care. All of the experimental protocols were approved by the Animal Care and Use Committee of Nagoya City University or by that of the University Miguel Hernandez and were performed according to the guidelines of the National Institutes of Health of Japan or of Spain, respectively. Jcl:ICR mice were obtained from Charles River Japan. The reeler mouse (B6C3Fe-a/a-Reln/rl/+) was purchased from The Jackson Laboratory. The yotari mouse was described previously (Sheldon et al., 1997). The ApoER2-deficient (B6;129S6-Lrp8 $\left.{ }^{\mathrm{tm} 1 \mathrm{Her}} / \mathrm{J}\right)$ and VLDLR-deficient (B6; 129S7-Vldlr ${ }^{\text {tm1Her } / J) ~ m i c e ~(T r o m m s d o r f f ~ e t ~ a l ., ~ 1999) ~ w e r e ~ g e n e r o u s ~ g i f t s ~}$ from J. Nimpf (Medical Universtiy of Vienna, Vienna, Austria).

Vector construction. Expression vectors for AP fusion of Reelin were constructed on pAPtag-5 (GenHunter) (Flanagan et al., 2000). The Reelin repeat (RR) was defined according to the computerized alignment (Ichihara et al., 2001). The Reelin cDNA construct, pCrl (D'Arcangelo et al., 1997), was used as a template for PCR amplification. For construction of the expression vector for AP fusion of the central fragment of Reelin, the DNA fragment encoding the N-terminal half of the third RR (RR3) was amplified by PCR with primers CCAGTCGACACTAGTACTTTGCCCCAGAACTTCTATG and GGTCTAGAATTCACTCCTATAAGGACATC (recognition sites for SalI and XbaI are underlined). The amplified product was digested with SalI and XbaI and subcloned into pAPtag-5 (pAP-RR3A). Separately, the DNA fragment encoding from the C-terminal half of RR3 to the $\mathrm{C}$ terminus of RR6 was amplified by PCR with primers CTTGGCCTGAAGTGTACG and CCTCTAGAGCCCGAGATGAGGACATTG ( $X b a \mathrm{I}$ site is underlined), and the amplified product was then subcloned into pCrl digested with BspEI and XbaI. This vector was digested with $\mathrm{XbaI}$, and subsequently a linker DNA encoding the FLAG epitope (DYKDDDDK) and a stop codon was inserted. This vector thus encodes a truncated Reelin protein that terminates at the end of RR6, with FLAG epitope on its C terminus. Finally, the AgeI/XbaI fragment was excised from this vector and subcloned into pAP-RR3A digested with the same enzymes, to generate the expression vector for AP-RR36. Methods for other AP-fusion expression vectors will be supplied on request. All sequences of the expression vectors were verified by DNA sequencing. Expression plasmids for ApoER2 (Nakano et al., 2007), VLDLR, and Dab1 (Morimura et al., 2005) were described previously.

Cell culture, transfection, and validation of AP-fusion probe. COS-7 and human embryonic kidney (HEK) 293T cells were grown in DMEM (Sigma) containing 10\% fetal calf serum (Equitech-Bio) and penicillin $(5000 \mathrm{U} / \mathrm{ml}) /$ streptomycin $(5 \mu \mathrm{g} / \mathrm{ml})$ (Invitrogen). Transfection was performed using Lipofectamine 2000 (Invitrogen) according to the instructions of the manufacturer. AP-fusion proteins were expressed in HEK293T cells. The supernatants were collected 2-3 d later, filtrated, and supplemented with sodium azide $(0.1 \%$ final), except for Dab1 phosphorylation assay. The absolute concentration of AP was determined as described previously (Flanagan et al., 2000). Preparation of Reelincontaining culture supernatant, SDS-PAGE, and Western blotting were performed as described previously (Nakano et al., 2007). For quantitative measurement of AP-RR36 binding to COS-7 cells (see Fig. $1 P$ ) or to primary cultured cortical neurons from reeler mice (supplemental Fig. 6, available at www.jneurosci.org as supplemental material), cells were pretreated as indicated in the figure legends and then incubated with APRR36 or control AP, washed, and heat inactivated as described above. They were then incubated with AP coloring buffer $[3.4 \mathrm{mg} / \mathrm{ml}$ Sigma phosphatase substrate (4-nitrophenyl phosphate disodium salt hexahydrate), $1 \mathrm{M}$ diethanolamine, $\mathrm{pH} 9.5$, and $0.5 \mathrm{mM} \mathrm{MgCl}_{2}$ ] for $20 \mathrm{~min}$ at room temperature. The reaction was stopped by adding $500 \mathrm{~mm}$ EDTA, and $\mathrm{OD}_{405}$ was measured. The values of control AP were subtracted from those of AP-RR36.

$A P$ in situ analyses. The whole procedures were performed essentially as described previously (Flanagan et al., 2000). Embryonic forebrain and postnatal cerebellum were cut with a VT1000S vibratome (Leica Microsystems) into $200 \mu \mathrm{m}$ unfixed sections. Embryonic cerebellum was sliced manually. The transfected COS-7 cells or the unfixed sections were incubated with AP-RR36 or control AP supernatants for $1 \mathrm{~h}$ at room temperature, washed six times for 5 min each with HBAH buffer [HBSS containing $0.5 \mathrm{mg} / \mathrm{ml}$ bovine serum albumin, $0.1 \%$ (w/v) sodium azide, and $20 \mathrm{~mm}$ HEPES], and fixed with acetone/formaldehyde fixative for $2 \mathrm{~min}$. The samples were washed twice with HEPES-buffered saline (in mM: $150 \mathrm{NaCl}$ and $20 \mathrm{HEPES}, \mathrm{pH} 7.0$ ), heated for $1 \mathrm{~h}$ at $65^{\circ} \mathrm{C}$ to inactivate endogenous AP, and washed with AP buffer (in mM: $100 \mathrm{NaCl}$, $5 \mathrm{MgCl}_{2}$, and 100 Tris, $\mathrm{pH} 9.5$ ). Cells or sections were stained for $2-4 \mathrm{~h}$ with $0.17 \mathrm{mg} / \mathrm{ml}$ 5-bromo-4-chloro-3-indolyl-phosphate (BCIP) and $0.33 \mathrm{mg} / \mathrm{ml}$ nitro blue tetrazolium (NBT) in AP buffer at room temperature. Immunostainings were performed before BCIP/NBT staining. Pictures were taken with a SZ-X7 stereoscopic microscope, an IX51-FL-S microscope (Olympus), a VB-6000/6010 digital microscope camera, or a BZ-9000 (Keyence).

Expression and purification of glutathione S-transferase fusion receptorassociated protein. Receptor-associated protein (RAP) is a common ligand for the low-density lipoprotein (LDL) receptor family and blocks the interaction between Reelin and ApoER2 or VLDLR (Herz et al., 1991, Andersen et al., 2003). For construction of the glutathione $S$-transferase (GST)-RAP expression vector, a DNA fragment encoding RAP was amplified by PCR with primers CCGAATTCTACTCGCGAGAGAAGAACGAGC and CCCTCGAGTCACCGAGCCCTTGAGACCCTGC (recognition sites for EcoRI and XhoI are underlined, respectively) with the mouse embryonic cDNA as a template. The amplified product was cloned into pGEX-4T-1 (GE Healthcare). All sequences of the expression vectors were verified by DNA sequencing. The Escherichia coli strain BL21 Codon Plus (Stratagene), which had been transformed with GST-RAP or control GST expression vector, was grown in Luria broth medium with $0.1 \mathrm{mg} / \mathrm{ml}$ ampicillin at $37^{\circ} \mathrm{C}$, and protein expression was induced by the addition of isopropyl- $\beta$-D-thiogalactopyranoside $(0.1$ $\mathrm{mm}$ final). Cells were incubated an additional $3 \mathrm{~h}$ and harvested by centrifugation. Cells were then resuspended in sonication buffer $(20 \mathrm{~mm}$ Tris, $\mathrm{pH}$ 8.0, $100 \mathrm{~mm} \mathrm{NaCl}, 2 \mathrm{~mm}$ EDTA, $0.1 \%$ Triton X-100, and $1 \mathrm{~mm}$ $\beta$-mercaptoethanol) and sonicated with a Branson Sonifier 250. The lysates were centrifuged, and the supernatant was collected. GST-RAP or control GST protein was purified with Glutathione Sepharose 4 Fast Flow (GE Healthcare) according to the instructions of the manufacturer but without detergent. The proteins were dialyzed against DMEM, and the protein concentration was determined by Quick Start Bradford Protein Assay kit (Bio-Rad).

Immunohistochemistry. Mouse brains at various developmental stages were immersion fixed overnight in $4 \%$ paraformaldehyde at $4^{\circ} \mathrm{C}$, cryoprotected in a series of sucrose solutions $(20-30 \%)$ in PBS at $4^{\circ} \mathrm{C}$. The brains were then embedded in Tissue-Tek OCT compound (Sakura Finetechnical) and sectioned at $14-16 \mu \mathrm{m}$ using the cryostat (CM 1850; Leica). Sections were blocked with $5 \%$ normal goat serum in Trisbuffered saline with $0.05 \%$ Tween 20 overnight at $4^{\circ} \mathrm{C}$, incubated with the indicated primary antibody for 5-6 h at room temperature or overnight at $4^{\circ} \mathrm{C}$, washed four times with Tris-buffered saline with $0.05 \%$ Tween 20 , and incubated with secondary antibody for $2 \mathrm{~h}$ at room temperature. Hoechst33342 ( $2 \mu \mathrm{g} / \mathrm{ml}$; Invitrogen) was used for nuclear staining. Samples were examined with IX51-FL-S or BZ-9000 microscopes.

Antibodies. The following primary antibodies were purchased and diluted as indicated: rabbit anti-AP serum (1:4000; BioMedTek), mouse 
anti-phosphotyrosine antibody 4G10 (1:1500; Upstate Biotechnology), rabbit anti-calretinin (1:1000; Millipore Bioscience Research Reagents), mouse anti-calbindin D-28K (1:1500; Sigma), and mouse anti-MAP2 (1:400; Sigma). The following secondary antibodies were used: peroxidaseconjugated anti-rabbit IgG, peroxidase-conjugated anti-mouse IgG (GE Healthcare), Alexa 488-conjugated anti-mouse IgG, Alexa 488-conjugated anti-rabbit IgG, and Alexa 594-conjugated anti-rabbit $\operatorname{IgG}$ (1:400; all from Invitrogen). Anti-RR5 antibody R5A (Jossin et al., 2007) was kindly provided by Dr. Goffinet (Catholic University of Leuven, Brussels, Belgium).

Anti-Dab1 was obtained as follows. Recombinant Dab1 protein, expressed in E. coli as GST-fusion protein, was purified using glutathione Sepharose and then released from GST by digesting with thrombin protease (GE Healthcare). This protein was used to immunize rabbits, and antiserum was recovered by Medical and Biological Laboratories.

RNA in situ hybridization. The sections were washed with PBS, postfixed with $4 \%$ paraformaldehyde, and treated with proteinase $\mathrm{K}$. The sections were then prehybridized with hybridization buffer (50\% formamide, $10 \%$ dextran sulfate, $0.1 \mathrm{mg} / \mathrm{ml}$ denatured salmon sperm DNA, $0.2 \mathrm{mg} / \mathrm{ml} \mathrm{SDS}$, and $2 \times \mathrm{SSC}$ ) for $15 \mathrm{~min}$ at $65^{\circ} \mathrm{C}$ and hybridized with an RNA probe in hybridization buffer overnight at $70^{\circ} \mathrm{C}$. After hybridization, the sections were washed with $5 \times$ SSC, $0.1 \times$ SSC and then incubated with $2 \%$ bovine serum albumin in NT buffer (in mм: 100 Tris, pH 7.5, and $150 \mathrm{NaCl})$. Thereafter, they were incubated with anti-digoxygenin-AP antibody (Roche Diagnostics), washed, and developed with BCIP/NBT. The probes used were as follows: nucleotides 10,039-10,668 (630 bp) for Reelin, nucleotides 1140-1906 (767 bp) for ApoER2, and nucleotides 460-1138 (679 bp) for VLDLR. These fragments were cloned into pBluescript II SK(-) (Stratagene), and digoxygenin-labeled RNA probes were prepared using a labeling kit (Roche Diagnostics) according to the protocol of the manufacturer.

\section{Results}

\section{Validation of AP-Reelin fusion protein}

The central fragment of Reelin (RR3 to RR6) is generated in vivo (Lambert de Rouvroit et al., 1999) and can bind to ApoER2 and VLDLR (Jossin et al., 2004). We fused the coding region for this fragment to that of heat- and fixation-resistant human placental AP (Flanagan et al., 2000) and expressed the resulting fusion protein in HEK293T cells (AP-RR36) (Fig. 1 A). This protein was detected in the conditioned medium as a major band of $\sim 240$ $\mathrm{kDa}$ by immunoblotting with anti-AP antibody, consistent with the combined size of the central fragment and AP (Fig. $1 B$, lane $2)$. The fusion protein consisting of the minimum receptorbinding unit of Reelin (RR5 to RR6) (Yasui et al., 2007) with AP was not effectively secreted from transfected HEK293T cells (data not shown) and thus was not used in the present study.

When the culture medium containing AP-RR36 and sodium azide (to block endocytosis) was applied to untransfected COS-7 cells that express neither ApoER2 nor VLDLR, no AP activity was detected (Fig. 1F). Conversely, COS-7 cells expressing either ApoER2 or VLDLR were clearly stained by AP-RR36 (Fig. 1G, H, respectively). Control AP alone bound to none of these cells (Fig. $1 C-E$ ). Cells expressing ApoER2 (Fig. $1 G, J$ ) always gave stronger signals than those expressing VLDLR (Fig. $1 H, K$ ) in AP-RR36 staining, which is reasonable because ApoER2 has much higher affinity to Reelin than VLDLR (Andersen et al., 2003). Addition of an excess amount of GST-RAP, which inhibits binding of Reelin to ApoER2 or VLDLR (Hiesberger et al., 1999), completely abolished this staining (Fig. $1 \mathrm{M}, N$ ). Coexpression of Dab1, which increases the surface amount of Reelin receptors (Morimura et al., 2005; Hoe et al., 2008), augmented this staining (supplemental Fig. 1, available at www.jneurosci.org as supplemental material). These results indicate that AP-RR36 can specifically and quantitatively detect FRR.
We next asked whether AP-RR36 could dismiss the prebound Reelin from the receptor. For this purpose, both AP-RR36 and Reelin were prepared from transfected HEK293T cells, and their amount was investigated with the antibody recognizing RR5 (Jossin et al., 2004). As shown in Figure 1O, the concentration of Reelin in this preparation was $\sim 0.5 \mathrm{~nm}$. COS-7 cells expressing ApoER2 or VLDLR were first incubated with the control medium or the one containing Reelin and then with AP-RR36 $(7.2 \mathrm{nM})$. Preincubation with Reelin did not decrease the binding of AP-RR36 (Fig. 1P). It was thus strongly suggested that excess amount of AP-RR36 can dismiss the prebound Reelin from the receptors. We further compared the signaling capacity of APRR36 with that of Reelin. AP-RR36 (0.5 nM) induced Dab1 phosphorylation (Fig. 1Q, lane 3), but it was less potent than Reelin at the same concentration (Fig. 1Q, lane 5). Thus, AP-RR36 can activate the downstream signaling of Reelin, but its activity was lower than full-length Reelin. This was consistent with our previous report that the $\mathrm{C}$-terminal region of Reelin, which is lacking in AP-RR36, is necessary for full signaling activity of Reelin (Nakano et al., 2007). AP-RR36 at high concentration (1.6 $\mathrm{nM}$ ) induced Dab1 phosphorylation as strongly as $0.5 \mathrm{~nm}$ Reelin. Serial and combinatorial applications of AP-RR36 and Reelin induced comparable level of Dab1 phosphorylation, suggesting that they activate the same receptor machinery (supplemental Fig. 2, available at www.jneurosci.org as supplemental material).

\section{FRRs in developing cerebral cortex}

At embryonic day 15.5 (E15.5), AP-RR36 stained most of the cortical wall (Fig. $2 \mathrm{~A}$ ), whereas control AP gave virtually no signal (Fig. 2C). The possibility that AP-RR36 bound to a molecule other than lipoprotein receptors was ruled out because the staining was abolished by addition of GST-RAP (Fig. 2D). The darkest staining was observed around the subventricular (SVZ) and intermediate (IZ) zones, respectively (Fig. 2 B). The area around the ventricular zone (VZ) was also faintly stained. The area closer to the surface, probably the cortical plate $(\mathrm{CP})$, was not obviously stained by AP-RR36. However, quite interestingly, a strong signal was observed in radial fibers perpendicular to the ventricular and pial surfaces (Fig. $2 B$ ). They may be either the radial glial fibers extending from the VZ or the leading processes of premigratory neurons, both of which have been proposed to be direct targets of Reelin (Hartfuss et al., 2003; Luque et al., 2003; Luque, 2007). We confirmed that AP-RR36 can dismiss Reelin from endogenously expressed FRR. Brain slices were treated with sodium azide, incubated with full-length Reelin $(0.5 \mathrm{nM})$, and then stained with AP-RR36. Pretreatment with Reelin did not significantly affect the staining signals (supplemental Fig. 3, available at www.jneurosci.org as supplemental material).

Because it was unexpected that the expression of FRRs would be barely detectable in the CP except for the radial fibers, we compared this staining pattern with expressions of Reelin, ApoER2, and VLDLR. At this stage, Reelin mRNA was expressed strongly in the MZ and weakly around the SVZ and IZ, as was reported previously (Fig. 2E,H) (Yoshida et al., 2006). ApoER2 mRNA was expressed mainly in the VZ/SVZ/IZ and weakly in the CP (Fig. $2 F, I$ ). These results are consistent with previous reports (Trommsdorff et al., 1999; Luque et al., 2003) and those found in public databases (http://www.genepaint.org). Conversely, VLDLR mRNA was mainly expressed in the CP (Fig. 2G,J). Therefore, it was strongly suggested that the strong AP-RR36 staining seen around the VZ/SVZ/IZ is attributable mostly to ApoER2. Indeed, most of the signal was abolished in the ApoER2-deficient cortical wall, whereas it remained virtually same in the VLDLR-deficient 


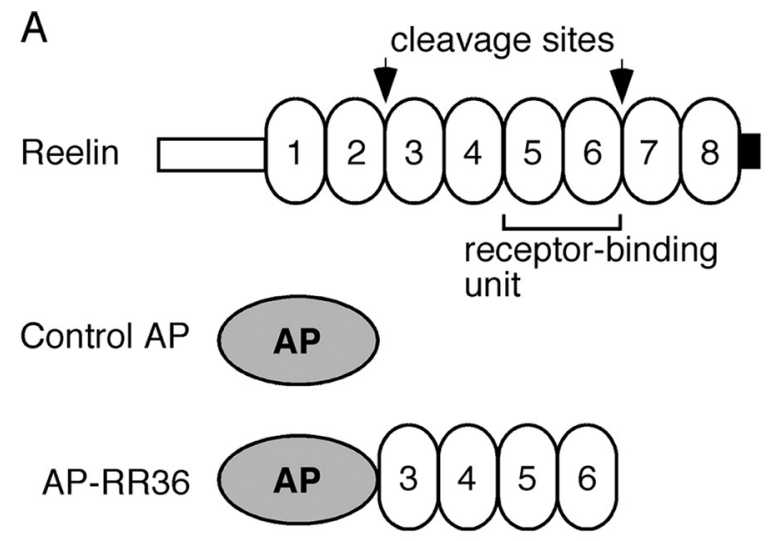

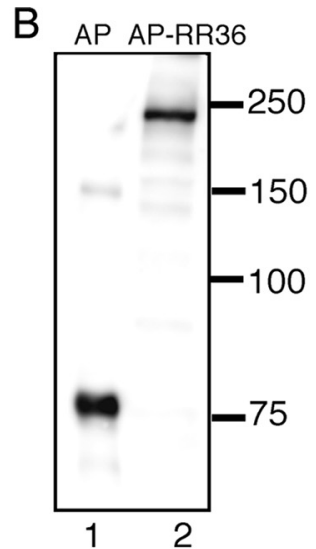

WB: anti-AP
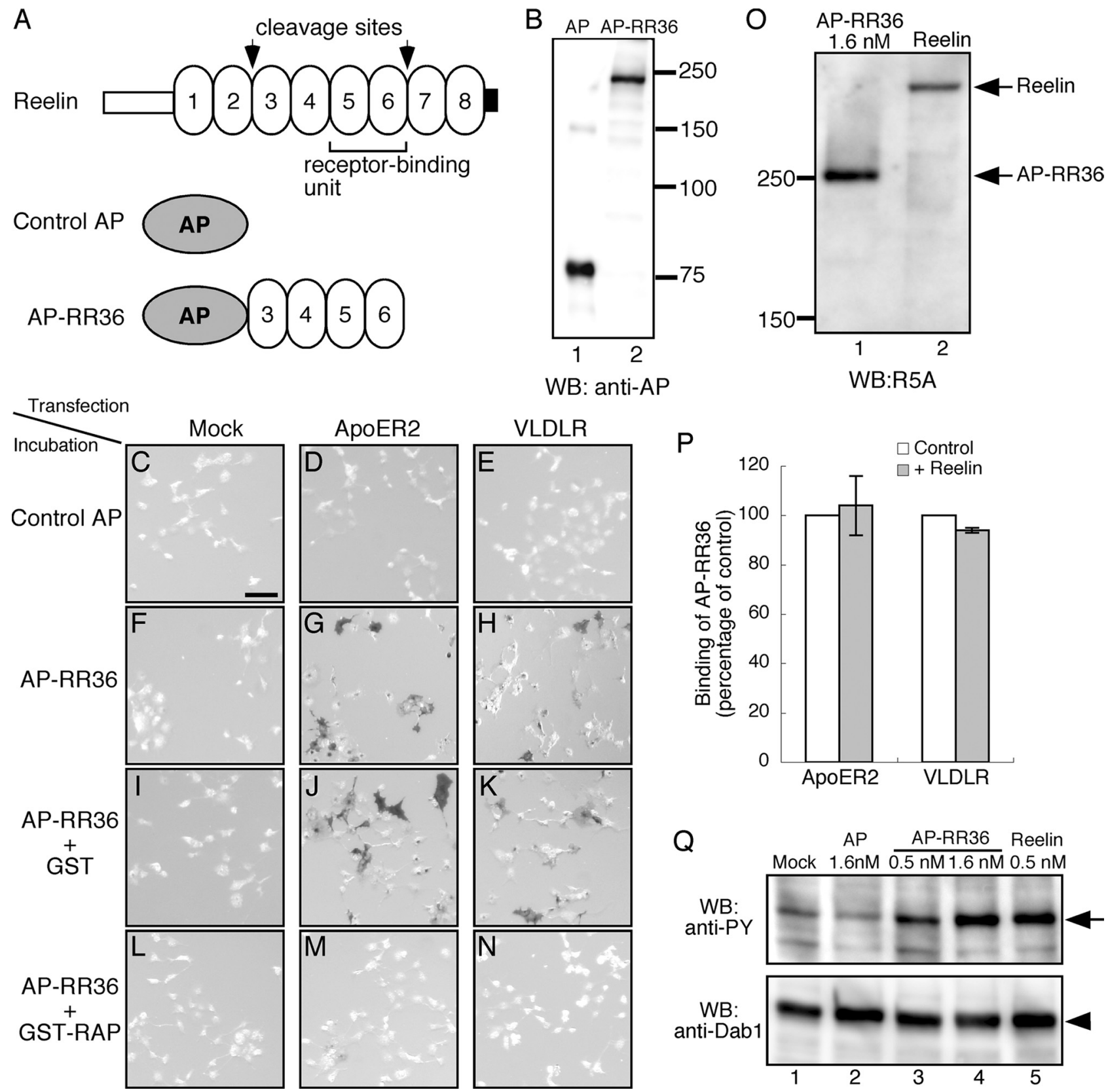

Figure 1. Construction of AP-RR36 and its ability to specifically detect FRRs. A, Schematic diagram of Reelin protein (top), control AP (middle), and AP-RR36 (bottom). Two sites that are cleaved in vivo by an unknown metalloprotease and minimum receptor-binding unit are shown in the top. B, Western blotting (WB) analysis. Culture supernatants containing either AP (lane 1) or AP-RR36 (lane 2) were separated by SDS-PAGE and proteins were transferred to a polyvinylidene difluoride membrane. The membrane was then incubated with anti-AP antibody, followed by incubation with HRP-conjugated secondary antibody and detection with a chemiluminescence kit. Positions of molecular weight markers are shown on the right in kilodaltons. $\mathbf{C}-\mathbf{N}$, AP-RR36 specifically binds to Reelin receptors. COS-7 cells were transfected with control vector $(\boldsymbol{C}, \boldsymbol{F}, \boldsymbol{I}, \boldsymbol{L})$, ApoER2 expression vector $(\boldsymbol{D}, \boldsymbol{G}, \boldsymbol{J}, \boldsymbol{M})$, or VLDLR expression vector $(\boldsymbol{E}, \boldsymbol{H}, \boldsymbol{K}, \boldsymbol{N})$. Two days later, the cells were incubated with control AP $(\boldsymbol{C}-\boldsymbol{E})$, AP-RR36 $(\boldsymbol{F}-\boldsymbol{H})$, AP-RR36 mixed with GST protein $(\boldsymbol{I}-\boldsymbol{K})$, or AP-RR36 mixed with GST-RAP $(\boldsymbol{L}-\boldsymbol{N})$. Cells expressing ApoER2 or VLDLR were stained with AP-RR36 (G, $\boldsymbol{H}$, respectively). This staining was not affected by addition of GST protein $(\boldsymbol{J}, \boldsymbol{K})$ but was virtually abolished by coincubation with GST-RAP $(\boldsymbol{M}, \boldsymbol{N}) . \mathbf{0}$, Estimation of Reelin concentration. AP-RR36 (lane 1, 1.6nm as calculated from AP-activity assay) (Flanagan et al., 2000) and Reelin (lane 2) were analyzed by Western blot using R5A antibody as described above.P, COS-7 cells expressing ApoER2 (left) or VLDLR (right) were incubated with culture medium from mock-transfected (white bars) or Reelin-transfected (gray bars) cells in the presence of sodium azide for 20 min. They were then incubated with AP-RR36, and the amount of its binding was quantitated as described in Materials and Methods $(n=3)$. Q, AP-RR36 induces phosphorylation of Dab1. Primary cortical neurons were incubated with the samples indicated above the lanes for $20 \mathrm{~min}$ at $37^{\circ} \mathrm{C}$, and Dab1 phosphorylation was measured as described previously (Nakano et al., 2007). PY, Phosphotyrosine. Scale bar (in C): C $-\mathbf{N}, 100 \mu \mathrm{m}$.

one (supplemental Fig. 4, available at www.jneurosci.org as supplemental material). It is of note that the diffuse expression of Reelin mRNA around the SVZ and IZ (Fig. 2E,H, arrowheads) (Yoshida et al., 2006) appeared to delineate the zone in which FRRs stop being abundantly expressed.

We next investigated FRR expression in other developmental stages. In addition, to more precisely assess the zone expressing
FRRs, we performed immunohistochemical analysis in combination with AP-RR36 staining. We found that the zone lacking strong staining expressed MAP2 (CP marker) at E15.5 (Fig. $3 B, C$ ). This was even more apparent at E17.5 (Fig. $3 F, G$ ). At E13.5, FRRs were rather uniformly expressed throughout the cortical wall except the MZ and deep VZ (Fig. 3A). Importantly, Dab1 protein was mainly present in the SVZ/IZ and fibers of the 

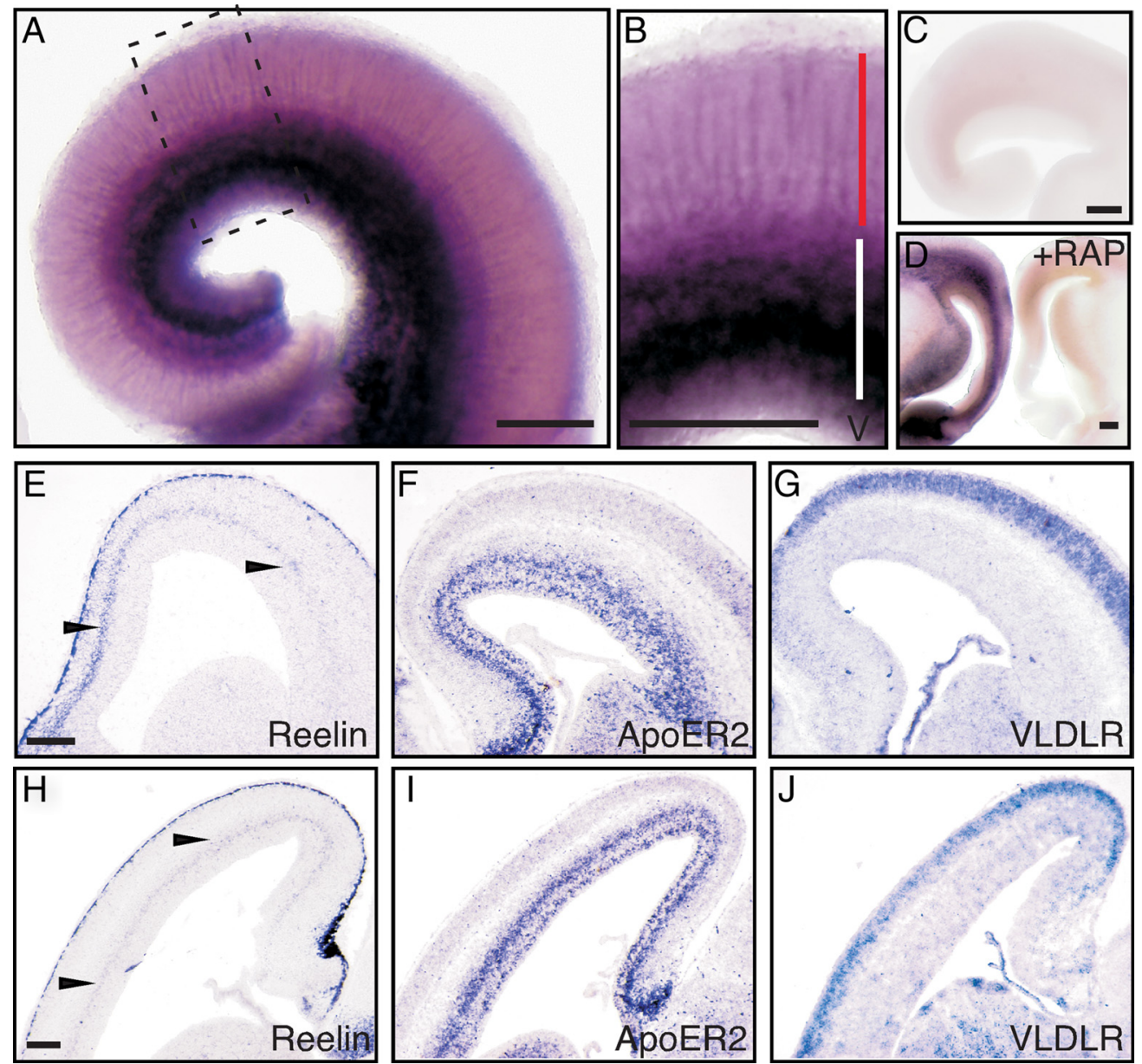

Figure 2. Localization of FRRs in the developing mouse cerebral cortex. $A, B, E 15.5$ mouse brains were cut coronally and stained with AP-RR36. A magnified view of the area surrounded by a broken line in $\boldsymbol{A}$ is shown in $\boldsymbol{B}$. Red and white bars in $\boldsymbol{B}$ indicate the region corresponding to the CP and IZ/SVZ, respectively. $\boldsymbol{C}$, The brain slice from the same mouse as in $\boldsymbol{A}$ was stained by control $A P$. D, The staining by AP-RR36 is abolished in the presence of GST-RAP. Slices from an E15.5 mouse brain were stained with AP-RR36 in the presence of control GST (left) or GST-RAP (right). E-J, Localization of mRNA in the E15.5 cerebral cortex. Coronal $(\boldsymbol{E}-\boldsymbol{G})$ or sagittal $(\boldsymbol{H}-\boldsymbol{J})$ slices were hybridized with antisense probes for Reelin $(\boldsymbol{E}, \boldsymbol{H})$, ApoER2 $(\boldsymbol{F}, \boldsymbol{I})$, or VLDLR $(\boldsymbol{G}, \boldsymbol{J})$. Note the diffuse Reelin mRNA signal around the $S V Z$ and $I Z$ (arrowheads in $\boldsymbol{E}, \boldsymbol{H})$. Most of the ApoER2 mRNA is localized in the VZ/SVZ/IZ $(\boldsymbol{F}, \boldsymbol{I})$, whereas the VLDLR mRNA is more abundantly expressed in the $C P(\boldsymbol{G}, \boldsymbol{J})$. Scale bars: $\boldsymbol{A}-\boldsymbol{D}, \boldsymbol{E}$ (for $\boldsymbol{E}-\boldsymbol{G}$ ), and $\boldsymbol{H}$ (for $\boldsymbol{H}-\boldsymbol{J}), 200 \mu \mathrm{m}$.
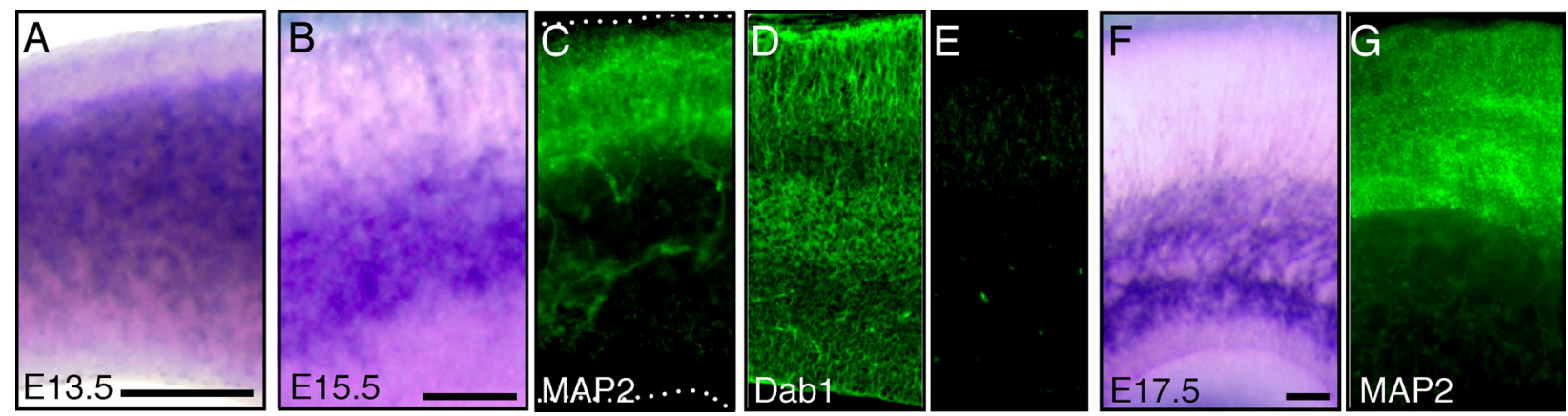

Figure 3. Comparison of the localization of FRRs with those of MAP2 and Dab1. A, E13.5 mouse brains were cut coronally and stained with AP-RR36. B, C, E15.5 mouse brain slices were stained with AP-RR36 (B) or with anti-MAP2 (C). D, E, Frozen brain sections $(14 \mu \mathrm{m})$ were immunostained with anti-Dab1 (D) or with control rabbit antibodies $(\boldsymbol{E})$. $\boldsymbol{F}, \boldsymbol{G}$, E17.5 mouse brain slices were stained with AP-RR36 (F) or with anti-MAP2 (G). Scale bars: $\boldsymbol{A}, \boldsymbol{B}$ (for $\boldsymbol{B}-\boldsymbol{E})$, and $\boldsymbol{F}($ for $\boldsymbol{F}, \boldsymbol{G}), 100 \mu \mathrm{m}$.

CP (Fig. 3D) at E15.5, consistent with a previous observation (Howell et al., 1999; Luque et al., 2003). Together, these observations confirmed that cells in the $\mathrm{CP}$, other than radial fibers, do not express abundant FRRs.

FRRs are more abundant in the cortical walls of reeler mice There are two possible explanations for why neurons in the CP were not strongly stained by AP-RR36. In the first scenario, translation, maturation, or trafficking of Reelin receptors are regulated so that they are only expressed on cell surfaces while they are in the SVZ and IZ, and they are downregulated before newborn neurons migrate into the $\mathrm{CP}$, regardless of the presence of Reelin. In the second case, the Reelin receptors are downregulated by Reelin binding, because Reelin is strongly expressed in the MZ and diffusely around the IZ (Fig. 2E,H) and Reelin activates the endocytosis of Reelin receptors (D'Arcangelo et al., 


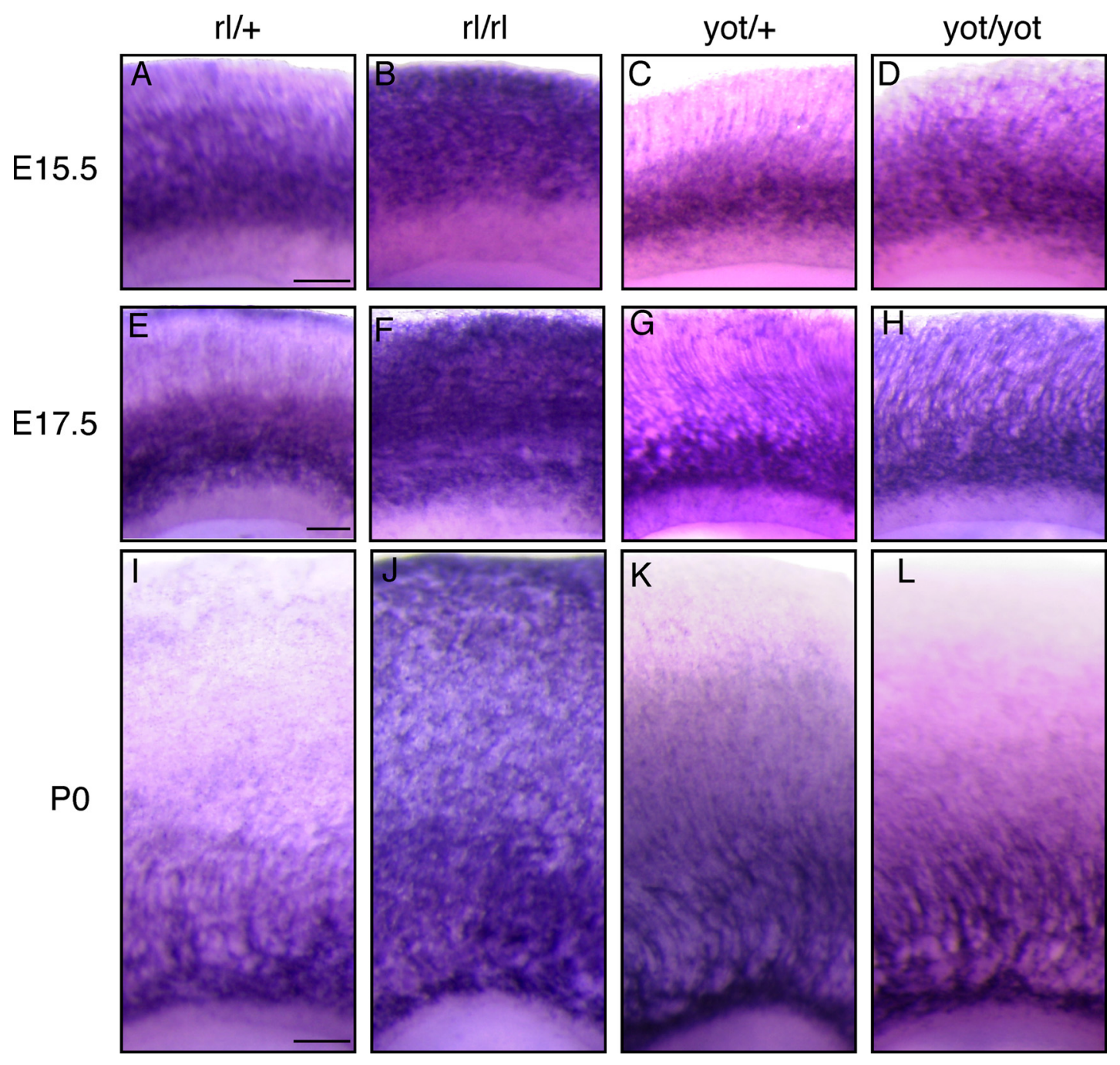

Figure 4. FRRs are increased in the cerebral cortex of reeler mouse but less in that of the yotari mouse. Brain slices from E15.5 (A-D), E17.5 (E-H), and P0 (I- $\boldsymbol{L})$ reeler mice $(\boldsymbol{r l} / \mathrm{rl}$; $\boldsymbol{B}$, $\boldsymbol{F}, \boldsymbol{J})$ or heterozygote littermates $(\mathrm{rl} /+; \boldsymbol{A}, \boldsymbol{E}, \boldsymbol{I})$, and yotari mice (yot/yot; $\boldsymbol{D}, \boldsymbol{H}, \boldsymbol{L})$ or heterozygote littermates $(\boldsymbol{C}, \boldsymbol{G}, \boldsymbol{K})$ were stained with $A \mathbf{P}-\mathrm{RR} 36$. Scale bars: $\boldsymbol{A}$ (for $\boldsymbol{A}-\boldsymbol{D}), \boldsymbol{E}($ for $\boldsymbol{E}-\boldsymbol{H})$, and $I$ (for $I-L), 100 \mu \mathrm{m}$.

1999; Morimura et al., 2005). To clarify this point, we investigated the amount and localization of FRRs in reeler and yotari mice, in which Reelin or Dab1 is deficient, respectively. Because reeler and yotari mice show almost indistinguishable phenotypes in the cerebral cortex, if the staining pattern differs between them, then the difference should be attributable to the deficiency of each gene rather than to abnormal architecture.

In the cortical wall of E15.5 reeler mouse, AP-RR36 staining gave strong signals even in the region close to MZ (Fig. $4 B$ ). In addition, the overall staining was much stronger than in the control [reeler heterozygous (rl/+)] slices (Fig. 4A). Similar results were obtained when cortical slices from E17.5 (Fig. $4 E, F$ ) or postnatal day $0(\mathrm{P} 0)$ (Fig. 4I,J) mice were used. These results suggest that FRRs persist on the CP neurons in reeler because they never encounter Reelin. The staining patterns were much less different between yotari and its heterozygous littermate (Fig. $4 C, D$ for E15.5, $G, H$ for E17.5, and $K, L$ for P0). Because yotari has a full complement of Reelin, these results indicated that the AP-RR36 staining in wild-type versus reeler mice reflects the in vivo situation of FRRs rather than a differential occupancy of the receptors by the endogenous Reelin. Incidentally, the amount and localization of mRNA for both ApoER2 and VLDLR did not differ significantly between the reeler and control cortex (supplemental Fig. 5, available at www.jneurosci.org as supplemental material). We also confirmed that Reelin downregulates FRRs in neurons. Primary cultured cortical neurons were prepared from reeler mice and incubated with exogenous Reelin, followed by quantitative measurement of AP-RR36 binding (supplemental Fig. 6, available at www.jneurosci.org as supplemental material). FRR is downregulated by $>70 \%$ in $24 \mathrm{~h}$, indicating that Reelin indeed induces downregulation of FRRs. These observations thus indicate FRRs to be downregulated after Reelin binding and, more importantly, that this downregulation occurs before the neurons migrate into the $\mathrm{CP}$.

\section{FRRs in the developing cerebellum of wild-type and reeler mice}

Reelin is indispensable for correct cerebellar formation, but its exact function at the molecular level is not fully understood. The expression patterns of Reelin and Dab1 are quite complex (Miyata et al., 1996; Rice et al., 1998; Perez-Garcia et al., 2004), and the cells and/or events regulated directly by Reelin signaling remain obscure. We thus tried to identify FRR localization by staining the developing cerebellum with AP-RR36. Because our 


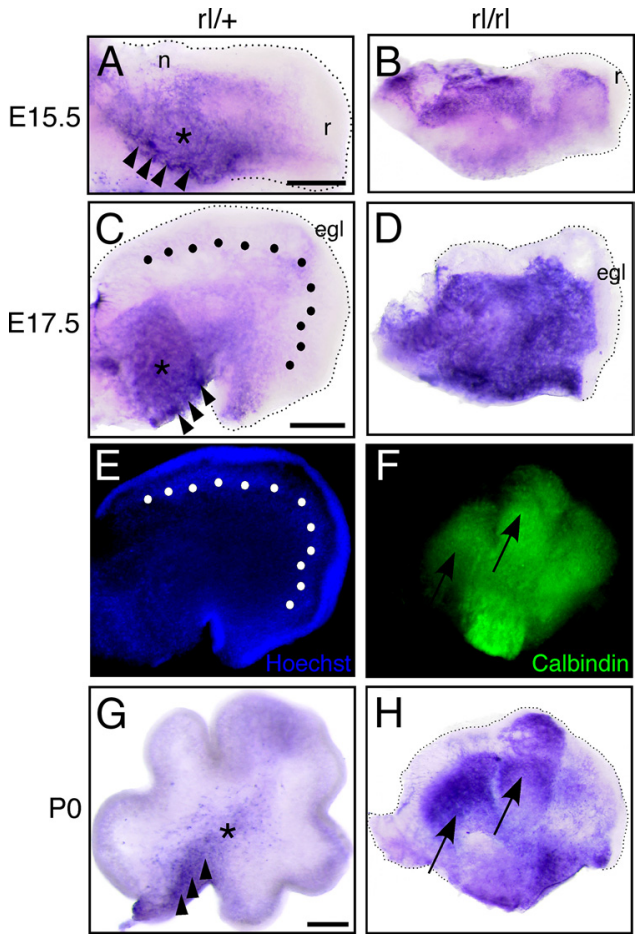

Figure 5. Localization of FRRs in the developing cerebellum of control and reeler mice. Sagittal slices from rl/ $+(\boldsymbol{A}, \boldsymbol{C}, \boldsymbol{G})$ or reeler $(\boldsymbol{B}, \boldsymbol{D}, \boldsymbol{H})$ mice at E15.5 $(\boldsymbol{A}, \boldsymbol{B}), \mathrm{E} 17.5(\boldsymbol{C}, \boldsymbol{D})$, or P0 $(\boldsymbol{G}$, $\boldsymbol{H})$ were stained with AP-RR36. The arrowheads and asterisk indicate the $C V Z$ and $D C N$, respectively. $n, r$, and egl indicate NTZ, RLS, and EGL, respectively. $\boldsymbol{E}$, The slice shown in C was stained with Hoechst33342. The dotted line in $\boldsymbol{C}$ and $\boldsymbol{E}$ indicates the position of Purkinje cells. $\boldsymbol{F}$, The slice shown in $\boldsymbol{H}$ was stained with anti-calbindin; arrows in $\boldsymbol{F}$ and $\boldsymbol{H}$ indicate clusters with high amounts of FRRs. Scale bars: in $\boldsymbol{A}$ (for $\boldsymbol{A}, \boldsymbol{B}), \boldsymbol{C}($ for $\boldsymbol{C}-\boldsymbol{E})$, and $\boldsymbol{G}($ for $\boldsymbol{F}-\boldsymbol{H}), 200 \mu \mathrm{m}$.

results for the cerebral cortex indicated downregulation of FRRs by Reelin to play an important role, we compared FRR expression between the reeler and normal cerebellum. At E15.5 in the rl/+ cerebellum, the cells in the cerebellar ventricular zone (CVZ), which produces Purkinje cells, were most densely stained (Fig. $5 A$, arrowheads), and the region around the deep cerebellar nuclei (DCN) was moderately stained (Fig. $5 A$, asterisk). The NTZ (Fig. $5 A, \mathrm{n}$ ) and the rostral rhombic lip migratory stream (RLS) (Fig. 5A, r) were not stained (Fig. 5A). In the reeler cerebellum, several clusters of cells showed strong staining, and these cells were intermingled with other clusters that did not express FRRs (Fig. 5B). RLS was not stained in the reeler cerebellum (Fig. 5B, r), too, indicating that the absence of RLS staining in the rl/+ cerebellum is independent of the presence of Reelin. At E17.5 in the $\mathrm{rl} /+$ cerebellum, FRR expression became rather restricted: the cells around the CVZ (Fig. 5C, arrowheads) and DCN (Fig. 5C, asterisk) were strongly stained by AP-RR36, whereas the rest of the cerebellum was only very faintly stained. Interestingly, Purkinje cells that begin aligning beneath the EGL (Fig. 5C,E, dots) did not express FRRs. It should be mentioned that, unlike in the cerebral cortex, no fibrous structure was obvious in the developing cerebellum. In the E17.5 reeler cerebellum, most of the cells were stained by AP-RR36, but there were some regions showing less staining, such as the RLS and NTZ (Fig. 5D). In the cerebellum of the $\mathrm{P} 0 \mathrm{rl} /+$ mouse, cells in the $\mathrm{CVZ}$ were strongly stained, whereas those of the DCN showed weak staining (Fig. 5G, arrowheads and asterisk, respectively). Conversely, in the cerebellum of the P0 reeler mouse, the cells expressing FRRs formed large aggregates (Fig. $5 \mathrm{H}$, arrows) and tended to segregate from those expressing no or little FRRs. Some, but not all, of the cells in the
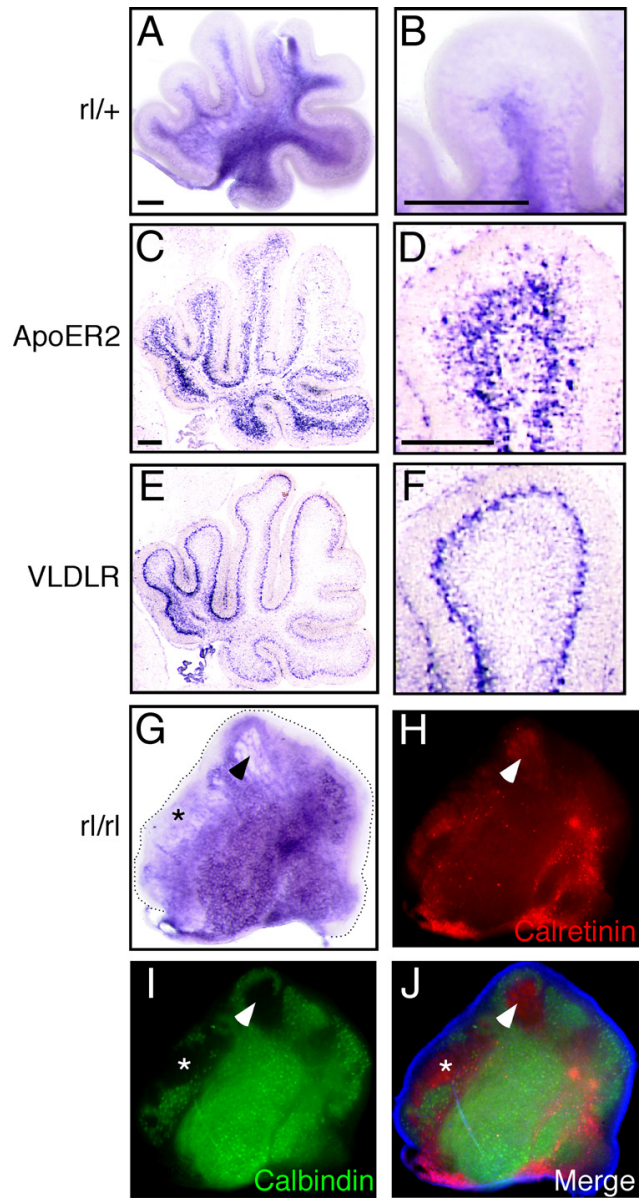

Figure 6. Localization of FRR in the postnatal cerebellum. $A, B, P 3$ cerebellar slice from $\mathrm{rl} /+$ mouse stained with AP-RR36. C, D, RNA in situ hybridization for ApoER2. $E, F$, RNA in situ hybridization for VLDLR. $\boldsymbol{B}, \boldsymbol{D}$, and $\boldsymbol{F}$ are magnified views of $\boldsymbol{A}, \boldsymbol{C}$, and $\boldsymbol{E}$, respectively. $\boldsymbol{G}-\boldsymbol{J}, \mathrm{P} 3$ cerebellar slices from reeler mouse stained with AP-RR36 $(\boldsymbol{G})$, anti-calretinin $(\boldsymbol{H})$, or anticalbindin (I). $\boldsymbol{J}$, A merged image of $\boldsymbol{H}, \boldsymbol{I}$, and Hoechst33342 staining (blue). Scale bars: $\boldsymbol{A}$ (for $\boldsymbol{A}$, $\boldsymbol{G}-J), \boldsymbol{B}, \boldsymbol{C}($ for $\boldsymbol{C}, \boldsymbol{E})$, and $\boldsymbol{D}($ for $\boldsymbol{D}, \boldsymbol{F}), 200 \mu \mathrm{m}$.

aggregates were Purkinje cells, as revealed by calbindin immunostaining (Fig. 5F). Calbindin-positive and FRR-positive cells also partially overlap in the yotari cerebellum at P0 (supplemental Fig. 7, available at www.jneurosci.org as supplemental material). These observations indicate that, in control mice, most Purkinje cells express FRRs only for a short period of time after they start migration in or around the CVZ and that FRRs are downregulated by virtue of Reelin before they begin aligning. In the absence of Reelin, most Purkinje cells fail to downregulate FRRs and form aggregates.

Whether or not Reelin signaling plays a role in postnatal development of the cerebellum is essentially unknown, although Reelin, ApoER2, VLDLR, and Dab1 are all highly expressed (Miyata et al., 1996; Rice et al., 1998; Darmanto et al., 2000; Perez-Garcia et al., 2004). Staining of P3 control cerebellum revealed that the DCN and internal granular layer (IGL) expressed FRR abundantly (Fig. 6A,B). Interestingly, mRNAs for ApoER2 and VLDLR were expressed mainly in the IGL and in Purkinje cells, respectively (Fig. 6C,E). In the P3 reeler cerebellum, several cells and clusters expressed FRRs (Fig. 6G). We found that most of the calretinin-positive cells, which probably include the DCN and unipolar brush cells (Ilijic et al., 2005; Fink et al., 2006), are FRR negative (Fig. 6G,H, arrowhead and asterisk). Calbindinpositive Purkinje cells, in turn, express FRR (Fig. 6I). Cells in the 
EGL expressed little FRR in either the control or the reeler cerebellum (Fig. 6A, G). These results indicate that FRR downregulation in postnatal Purkinje cells under normal conditions is at least partly dependent on Reelin and that DCN continues to be the primary Reelin target in the postnatal period.

\section{Discussion}

The main findings of this work can be summarized as follows: (1) in the developing cerebral cortex, cells in the SVZ and IZ are competent to receive Reelin; (2) FRR downregulation occurs after binding to Reelin in vivo, resulting in the neuronal cell bodies in the CP having little FRRs; (3) FRR and Dab1 protein are present in fiber-like structures of the $\mathrm{CP}$, supporting the idea that Reelin directly affects the radial glial fibers and/or the leading processes of premigratory or migrating projection neurons; (4) not only Purkinje cells but also other types of cells express FRRs in the embryonic cerebellum; (5) in the developing cerebellum, FRRs are downregulated after they bind to Reelin in most Purkinje cells, which occurs as soon as they migrate out of the CVZ.

\section{AP-RR36 as a reliable probe for in situ detection and quantification of FRRs}

AP-fusion probes have been extensively used to quantitatively locate binding molecules in the extracellular milieu (Flanagan et al., 2000). The probe we devised to investigate the expression of FRRs, AP-RR36, includes the central fragment of Reelin, which is generated in vivo, efficiently secreted from cultured cells, stable (up to 6 months at $4^{\circ} \mathrm{C}$ ), and specifically binds to ApoER2 and VLDLR (Fig. 1). Importantly, all the signals identified in brain slices using AP-RR36 are abolished by an excess amount of GST-RAP (Fig. 2D), a common ligand for the LDL receptor family. Among the family, ApoER2 and VLDLR are the only members that are known to bind Reelin. LDL receptor is structurally similar to ApoER2 and VLDLR but does not bind Reelin (D’Arcangelo et al., 1999; Jossin et al., 2004). Other members of the family have rather different structures. Therefore, it is reasonable to conclude that AP-RR36 specifically detects the total amount of ApoER2 plus VLDLR in the developing brain. Unfortunately, AP-RR36 stains neither fixed tissue nor frozen sections (data not shown), and it requires heat treatment of the samples. Therefore, not all antibodies are compatible with AP-RR36 staining, making identification of the cells and/or structures in the slices difficult.

\section{FRR expression and the site of Reelin action in the cerebral cortex}

Despite intensive research, the primary role of Reelin during corticogenesis remains a matter of debate. The original finding that Reelin is exclusively expressed in the MZ (D'Arcangelo et al., 1995; Ogawa et al., 1995) generated many models stressing the importance of Reelin function at the end of migration of each neuron (Tissir and Goffinet, 2003; Soriano and Del Río, 2005; Cooper, 2008). Our results, however, indicate that, in the cerebral cortex, FRRs are present in radially migratory neurons in the SVZ/IZ and/or in their processes (Fig. 7A). The newborn neurons encounter Reelin before or around the time of passage through the IZ and, importantly, downregulate FRR. By the time they enter the CP, they have few FRRs. The expression pattern of Dab1 protein (Fig. 3D) (Rice et al., 1998) and the fact that Dab1 is phosphorylated around the VZ (Magdaleno et al., 2002) are consistent with this model. Reelin may diffuse from the MZ to the IZ and downregulate FRRs, or Reelin secreted from the IZ itself (Fig. $2 E, H)$ may have some role, considering that massive loss of

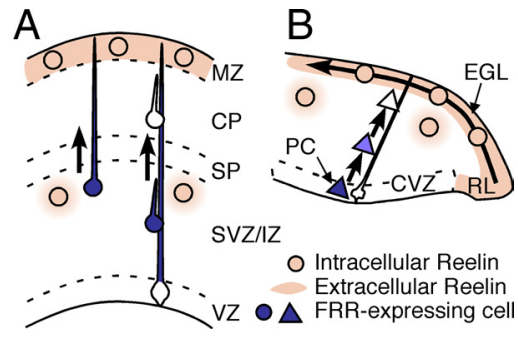

Figure 7. Proposed model of Reelin actions. For details, see Discussion. MZ, Marginal zone; $C P$, cortical plate; SP, subplate; IZ, intermediate zone; SVZ, subventricular zone; VZ, ventricular zone; PC, Purkinje cell; CVZ, cerebellar ventricular zone; EGL, external granular layer; RL, rhombic lip.

Cajal-Retzius cells in the MZ has little impact on cortical layering (Yoshida et al., 2006). The radial glial cells and/or intermediate progenitor cells whose cell bodies are located in the VZ/SVZ may have FRRs in their radial fibers, and Reelin may signal through them. This may be important for correct differentiation or for migration. The identification of the processes and its physiological significance are under study in our laboratories. Finally, we do not exclude that small amount of FRRs remaining expressed in $\mathrm{CP}$ cells play a role.

\section{FRR expression and the targets of Reelin in the cerebellum}

Genetic evidence indicates that there are two main differences between cerebral and cerebellar development with respect to Reelin function. First, cell non-autonomous function of Dab1 ("community effect") is apparent in cerebellar Purkinje cell migration (Yang et al., 2002), although it does not appear very clearly in cerebral development (Hammond et al., 2001; Olson et al., 2006). Second, ectopic expression of Reelin in the cerebral VZ only partially rescues preplate splitting but not the layering pattern in the cerebral cortex, whereas that in the CVZ greatly alleviates Purkinje cell migration and cerebellar foliation (Magdaleno et al., 2002). Thus, the action of Reelin may differ fundamentally between the cerebral cortex and cerebellum. It has been established that Reelin is required for correct migration of Purkinje cells (Goffinet, 1983; Goffinet et al., 1984; Miyata et al., 1997), but when and where Reelin acts on these cells are unknown. It was demonstrated previously that Purkinje cells are responsive to Reelin even before they begin migrating (Miyata et al., 1997). The strong expression of FRRs in the CVZ is consistent with this notion. Moreover, the absence of FRRs in Purkinje cells that begin aligning beneath the EGL (Fig. 5) indicates that the function of Reelin in Purkinje cell migration is fulfilled in the early stage. This idea is also supported by observations in the math1-mutant mouse that EGL-derived Reelin (i.e., Reelin that is close to the "goal" region) does not play a central role in Purkinje cell positioning (Jensen et al., 2002). We consider this to be consistent with the concept that, in the cerebral cortex, Reelin functions on premigratory neurons or neurons just beginning to migrate. Thus, despite obvious morphogenetic differences between cerebral cortical and cerebellar development, our results point to a common underlying principle during development of the cerebral cortex and cerebellum: Reelin controls the migration of long projection neurons via regulated expression and downregulation of FRRs.

We also shown that the DCN express substantial amounts of FRRs throughout development. DCN cells may come from the CVZ (Altman and Bayer, 1985) and/or the RLS/NTZ (Fink et al., 2006). Because the RLS and NTZ contain no FRRs, the FRR- 
positive DCN cells may be derived from the CVZ. The structure of the DCN is abnormal in the reeler cerebellum (Goffinet, 1983; Goffinet et al., 1984). Although it is possible that this abnormality is a secondary effect of Purkinje cell misplacement, Reelin may have a direct effect on the formation of DCN, because they also express Dab1 protein (Rice et al., 1998). In addition, FRRs persist in the postnatal cerebellum (Fig. 6). Their function is unknown, but they may play some role in synaptic function, as they do in the postnatal cerebral cortex (Herz and Chen, 2006).

Our results regarding the localization of FRRs in Purkinje cell migration are summarized in Figure $7 B$. Purkinje cells born in the CVZ express FRRs, but they downregulate FRRs relatively quickly as they disperse and migrate toward the EGL. This downregulation is at least partly dependent on Reelin. Reelin is expressed in the EGL and in other areas (D'Arcangelo et al., 1995; Miyata et al., 1996; Rice et al., 1998), the source of which is physiologically important remains to be investigated.

\section{Concluding remarks}

Recent analyses of Reelin functions all indicate that the role(s) of Reelin in the developing brain is far from simple. However, one idea becoming increasingly plausible is that Reelin crucially acts on neurons just as they begin to migrate. The precisely regulated expression and downregulation of FRRs strongly suggests that the primary Reelin action occurs on projection neurons at their early/premigratory stage in both developing cerebral cortex and cerebellum. These results point to the universal and simple action of Reelin in the developing brain.

\section{References}

Altman J, Bayer SA (1985) Embryonic development of the rat cerebellum. II. Translocation and regional distribution of the deep neurons. J Comp Neurol 231:27-41.

Andersen OM, Benhayon D, Curran T, Willnow TE (2003) Differential binding of ligands to the apolipoprotein E receptor 2. Biochemistry 42:9355-9364.

Benhayon D, Magdaleno S, Curran T (2003) Binding of purified Reelin to ApoER2 and VLDLR mediates tyrosine phosphorylation of Disabled-1. Brain Res Mol Brain Res 112:33-45.

Cooper JA (2008) A mechanism for inside-out lamination in the neocortex. Trends Neurosci 31:113-119.

D’Arcangelo G, Miao GG, Chen SC, Soares HD, Morgan JI, Curran T (1995) A protein related to extracellular matrix proteins deleted in the mouse mutant reeler. Nature 374:719-723.

D’Arcangelo G, Nakajima K, Miyata T, Ogawa M, Mikoshiba K, Curran T (1997) Reelin is a secreted glycoprotein recognized by the CR-50 monoclonal antibody. J Neurosci 17:23-31.

D’Arcangelo G, Homayouni R, Keshvara L, Rice DS, Sheldon M, Curran T (1999) Reelin is a ligand for lipoprotein receptors. Neuron 24:471-479.

Darmanto W, Inouye M, Takagishi Y, Ogawa M, Mikoshiba K, Murata Y (2000) Derangement of Purkinje cells in the rat cerebellum following prenatal exposure to X-irradiation: decreased Reelin level is a possible cause. J Neuropathol Exp Neurol 59:251-262.

Feng L, Allen NS, Simo S, Cooper JA (2007) Cullin 5 regulates Dab1 protein levels and neuron positioning during cortical development. Genes Dev 21:2717-2730.

Fink AJ, Englund C, Daza RA, Pham D, Lau C, Nivison M, Kowalczyk T, Hevner RF (2006) Development of the deep cerebellar nuclei: transcription factors and cell migration from the rhombic lip. J Neurosci 26:3066-3076.

Flanagan JG, Cheng HJ, Feldheim DA, Hattori M, Lu Q, Vanderhaeghen P (2000) Alkaline phosphatase fusions of ligands or receptors as in situ probes for staining of cells, tissues, and embryos. Methods Enzymol 327:19-35.

Goffinet AM (1983) The embryonic development of the cerebellum in normal and reeler mutant mice. Anat Embryol 168:73-86.

Goffinet AM, So KF, Yamamoto M, Edwards M, Caviness VS Jr (1984) Ar- chitectonic and hodological organization of the cerebellum in reeler mutant mice. Brain Res 318:263-276.

Hack I, Hellwig S, Junghans D, Brunne B, Bock HH, Zhao S, Frotscher M (2007) Divergent roles of ApoER2 and Vldlr in the migration of cortical neurons. Development 134:3883-3891.

Hammond V, Howell B, Godinho L, Tan SS (2001) disabled-1 functions cell autonomously during radial migration and cortical layering of pyramidal neurons. J Neurosci 21:8798-8808.

Hartfuss E, Förster E, Bock HH, Hack MA, Leprince P, Luque JM, Herz J, Frotscher M, Götz M (2003) Reelin signaling directly affects radial glia morphology and biochemical maturation. Development 130:4597-4609.

Herz J, Chen Y (2006) Reelin, lipoprotein receptors and synaptic plasticity. Nat Rev Neurosci 7:850-859.

Herz J, Goldstein JL, Strickland DK, Ho YK, Brown MS (1991) 39-kDa protein modulates binding of ligands to low density lipoprotein receptor-related protein/alpha 2-macroglobulin receptor. J Biol Chem 266:21232-21238.

Hiesberger T, Trommsdorff M, Howell BW, Goffinet A, Mumby MC, Cooper JA, Herz J (1999) Direct binding of Reelin to VLDL receptor and ApoE receptor 2 induces tyrosine phosphorylation of disabled- 1 and modulates tau phosphorylation. Neuron 24:481-489.

Hoe HS, Minami SS, Makarova A, Lee J, Hyman BT, Matsuoka Y, Rebeck GW (2008) Fyn modulation of Dab1 effects on amyloid precursor protein and ApoE receptor 2 processing. J Biol Chem 283:6288-6299.

Howell BW, Herrick TM, Cooper JA (1999) Reelin-induced tyrosine phosphorylation of disabled 1 during neuronal positioning. Genes Dev 13:643-648.

Ichihara H, Jingami H, Toh H (2001) Three novel repetitive units of reelin. Brain Res Mol Brain Res 97:190-193.

Ilijic E, Guidotti A, Mugnaini E (2005) Moving up or moving down? Malpositioned cerebellar unipolar brush cells in reeler mouse. Neuroscience 136:633-647.

Jensen P, Zoghbi HY, Goldowitz D (2002) Dissection of the cellular and molecular events that position cerebellar Purkinje cells: a study of the math1 null-mutant mouse. J Neurosci 22:8110-8116.

Jossin Y, Ignatova N, Hiesberger T, Herz J, Lambert de Rouvroit C, Goffinet AM (2004) The central fragment of Reelin, generated by proteolytic processing in vivo, is critical to its function during cortical plate development. J Neurosci 24:514-521.

Jossin Y, Gui L, Goffinet AM (2007) Processing of Reelin by embryonic neurons is important for function in tissue but not in dissociated cultured neurons. J Neurosci 27:4243-4252.

Lambert de Rouvroit C, de Bergeyck V, Cortvrindt C, Bar I, Eeckhout Y, Goffinet AM (1999) Reelin, the extracellular matrix protein deficient in reeler mutant mice, is processed by a metalloproteinase. Exp Neurol $156: 214-217$

Luque JM (2007) Puzzling out the reeler brainteaser: does reelin signal to unique neural lineages? Brain Res 1140:41-50.

Luque JM, Morante-Oria J, Fairén A (2003) Localization of ApoER2, VLDLR and Dab1 in radial glia: groundwork for a new model of reelin action during cortical development. Brain Res Dev Brain Res 140:195-203.

Magdaleno S, Keshvara L, Curran T (2002) Rescue of ataxia and preplate splitting by ectopic expression of Reelin in reeler mice. Neuron 33:573-586.

Miyata T, Nakajima K, Aruga J, Takahashi S, Ikenaka K, Mikoshiba K, Ogawa M (1996) Distribution of a reeler gene-related antigen in the developing cerebellum: an immunohistochemical study with an allogeneic antibody CR-50 on normal and reeler mice. J Comp Neurol 372:215-228.

Miyata T, Nakajima K, Mikoshiba K, Ogawa M (1997) Regulation of Purkinje cell alignment by reelin as revealed with CR-50 antibody. J Neurosci 17:3599-3609.

Morimura T, Hattori M, Ogawa M, Mikoshiba K (2005) Disabled1 regulates the intracellular trafficking of reelin receptors. J Biol Chem 280:16901-16908.

Nakano Y, Kohno T, Hibi T, Kohno S, Baba A, Mikoshiba K, Nakajima K, Hattori M (2007) The extremely conserved C-terminal region of Reelin is not necessary for secretion but is required for efficient activation of downstream signaling. J Biol Chem 282:20544-20552.

Ogawa M, Miyata T, Nakajima K, Yagyu K, Seike M, Ikenaka K, Yamamoto H, Mikoshiba K (1995) The reeler gene-associated antigen on Cajal- 
Retzius neurons is a crucial molecule for laminar organization of cortical neurons. Neuron 14:899-912.

Olson EC, Kim S, Walsh CA (2006) Impaired neuronal positioning and dendritogenesis in the neocortex after cell-autonomous Dab1 suppression. J Neurosci 26:1767-1775.

Perez-Garcia CG, Tissir F, Goffinet AM, Meyer G (2004) Reelin receptors in developing laminated brain structures of mouse and human. Eur J Neurosci 20:2827-2832.

Rice DS, Sheldon M, D’Arcangelo G, Nakajima K, Goldowitz D, Curran T (1998) Disabled-1 acts downstream of Reelin in a signaling pathway that controls laminar organization in the mammalian brain. Development 125:3719-3729.

Sheldon M, Rice DS, D’Arcangelo G, Yoneshima H, Nakajima K, Mikoshiba K, Howell BW, Cooper JA, Goldowitz D, Curran T (1997) Scrambler and yotari disrupt the disabled gene and produce a reeler-like phenotype in mice. Nature 389:730-733.

Soriano E, Del Río JA (2005) The cells of Cajal-Retzius: still a mystery one century after. Neuron 46:389-394.
Stolt PC, Bock HH (2006) Modulation of lipoprotein receptor functions by intracellular adaptor proteins. Cell Signal 18:1560-1571.

Tissir F, Goffinet AM (2003) Reelin and brain development. Nat Rev Neurosci 4:496-505.

Trommsdorff M, Gotthardt M, Hiesberger T, Shelton J, Stockinger W, Nimpf J, Hammer RE, Richardson JA, Herz J (1999) Reeler/Disabled-like disruption of neuronal migration in knockout mice lacking the VLDL receptor and ApoE receptor 2. Cell 97:689-701.

Yang H, Jensen P, Goldowitz D (2002) The community effect and Purkinje cell migration in the cerebellar cortex: analysis of scrambler chimeric mice. J Neurosci 22:464-470.

Yasui N, Nogi T, Kitao T, Nakano Y, Hattori M, Takagi J (2007) Structure of a receptor-binding fragment of reelin and mutational analysis reveal a recognition mechanism similar to endocytic receptors. Proc Natl Acad Sci U S A 104:9988-9993.

Yoshida M, Assimacopoulos S, Jones KR, Grove EA (2006) Massive loss of Cajal-Retzius cells does not disrupt neocortical layer order. Development 133:537-545. 